\title{
Long-acting insulin in a public health system: analysis of compliance with clinical protocol in public pharmacies
}

\author{
Insulina de ação prolongada no sistema público de saúde: \\ análise da adesão ao protocolo clínico em farmácias públicas
}

Tadeu Uggere de Andrade (https://orcid.org/0000-0001-6387-7895) ${ }^{1}$

Fabrício Soares Moreira (https://orcid.org/0000-0001-9404-7464) ${ }^{1}$

Karla Oliveira dos Santos Cassaro (https://orcid.org/0000-0001-9125-0854) ${ }^{1}$

Manuela Martins Cruz (https://orcid.org/0000-0002-7024-2174) ${ }^{1}$

Girlandia Alexandre Brasil (https://orcid.org/0000-0002-5455-7141) ${ }^{1}$

Ewelyne Miranda de Lima (https://orcid.org/0000-0003-1497-6111) ${ }^{1}$

Dominik Lenz (https://orcid.org/0000-0001-6932-401X) ${ }^{1}$

Denise Coutinho Endringer (https://orcid.org/0000-0001-9396-2097) ${ }^{1}$

${ }^{1}$ Departamento de Ciências Farmacêuticas, Universidade Vila Velha. Rua

Comissário José Dantas de

Melo 21, Boa Vista. 29102

770 Vila Velha ES Brasil.

tadeu.uggere@uvv.br

\begin{abstract}
Diabetes mellitus (DM) is a chronic disease marked by elevated blood glucose levels. Controlling DM involves adequate diet, physical exercises, medicines and monitoring the blood glucose and glycated hemoglobin (HbAlc) levels. This was a retrospective study of the process of dispensing long-acting insulin analogues to users with diabetes (types 1 and 2) who were registered at high-cost public pharmacies in public health system in a southeast state of Brazil, that sought to evaluate the fulfilment of the criteria of all the clinical protocol to provide these analogs. Of the 987 users registered in the health service, 315 met the inclusion criteria for the study. The evaluation of the dispensing processes of the long-acting insulin analogues revealed that the inclusion, exclusion, and suspension criteria of the protocol related with these insulin analogues were in some extend only partially fulfilled. Additionally, there was no difference between the initial and final fasting glycemic and HbAlc levels. It is concluded that the established criteria for dispensing long-acting insulin analogues were partly fulfilled by pharmacies, compromising the rational use of these analogues. It can directly impact the cost of maintaining the public health service and users' health.

Key words Insulin long-acting, Diabetes mellitus, Clinical protocols
\end{abstract}

Resumo Diabetes mellitus (DM) é uma doença crônica marcada por níveis sanguíneos elevados de glicose. O controle do DM envolve dieta adequada, exercícios físicos, medicamentos e monitoramento dos niveis sanguíneos de glicose e de hemoglobina glicada (HbA1c). Trata-se de um estudo retrospectivo do processo de dispensação de análogos de insulina de ação prolongada a usuários com diabetes (tipos 1 e 2) cadastrados em farmácias públicas de alto custo do sistema público de saúde de um estado do Sudeste do Brasil, que buscou avaliar o cumprimento dos critérios do protocolo clínico para fornecimento desses análogos. Dos 987 usuários cadastrados no serviço de saúde, 315 preencheram os critérios de inclusão. A avaliação dos processos de dispensação dos análogos de insulina de ação prolongada revelou que os critérios de inclusão, exclusão e suspensão do protocolo dos análogos de insulina eram parcialmente cumpridos. Além disso, não houve diferença entre os niveis inicial e final de glicemia em jejum e HbA1c. Conclui-se que os critérios estabelecidos para dispensação de análogos de insulina de ação prolongada foram parcialmente cumpridos pelas farmácias, comprometendo o uso racional dos análogos. Os achados podem impactar diretamente no custo de manutenção do serviço público de saúde e na saúde do usuário.

Palavras-chave Insulina de ação prolongada, Diabetes mellitus, Protocolos clínicos 


\section{Introduction}

Diabetes Mellitus (DM) is a chronic disease marked by elevated blood glucose levels, which occur due to a deficiency in insulin secretion, a compromised hormone action, or both factors ${ }^{1,2}$. According to the World Health Organization $(\mathrm{WHO})^{2}$, in 2014, 422 million adults were diagnosed with diabetes worldwide. The International Diabetes Federation (IDF) ${ }^{3}$ estimates that in 2040 this number will increase to 642 million people. Brazil has 14.3 million users with diabetes; the country is ranking number four worldwide ${ }^{3}$.

Controlling DM involves an adequate diet, physical exercise, medicines and monitoring the blood glucose and glycated hemoglobin (HbAlc) levels ${ }^{4}$. Users' care is difficult, especially the prevention of complications, such as retinopathy, cardiovascular disease, nephropathy, and others.

Assisting a user with DM generates a great economic and social impact ${ }^{6}$. According to the $\mathrm{IDF}^{2}$, most countries spend between $5 \%$ and $20 \%$ of their health expenditure on diabetes. This demand well organized public health systems due to the financial burdens on insulins and other treatments ${ }^{3}$; especially insulin analogues, which are increasingly prescribed due to their advantage over the others ${ }^{2}$, and even to treat chronic secondary complications ${ }^{7}$.

Thus, it is necessary to elaborate policies that establish criteria for the diagnosis and treatment of the disease. The use of clinical protocols and therapeutic guidelines (CPTG) to standardize users' care is a strategy for qualifying the supply and management of actions in health services ${ }^{8}$.

According to Vinicor ${ }^{9}$, cost reduction and better DM care are achieved through four key points: primary prevention, early diagnosis, guaranteed access and use of the health service and the quality of care provided. Efficient observance encompasses educational actions, the competence of the professionals involved and the availability of medicines and supplies in a sufficient quantity to meet the demand ${ }^{10}$.

The standardization of the health care service, when the process is based on evidence, makes it possible to use appropriate therapeutics approaches and generate positive impacts directly on the users' health ${ }^{11}$. According to the WHO, the care provided by the health services must consider local needs and resources as well as the continuous evaluation of the effectiveness and quality of the treatment ${ }^{12}$.

Then, the establishment of the CPTG by public health services is an important tool for rationalizing resources ${ }^{13}$, especially with highcost medicines such as long-acting insulin ana$\operatorname{logues}^{14}$. It must be guaranteed that the practices in the health service are based on the tenets established in the CPTGs. However, a study that has evaluated the effective fulfillment of all the criteria recommended by the CPTG to provide these analogues in a public health system is not yet established in the literature. Therefore, the present study aimed to evaluate whether the criteria established in the CPTGs for long-acting insulin supply in a public health service are being fulfilled by the public pharmacies dispensing high-cost medicines.

\section{Methods}

\section{Type and object of study}

This is a retrospective study of administrative process of users with diabetes type I and II receiving long-acting insulin analogues (insulin glargine and insulin detemir) in high-cost medicines dispensing pharmacies in a public system in a southeastern state of Brazil.

\section{Description of place of study}

The public health system in Brazil, called the Unified Health System (SUS), follows defined pharmaceutical policies, The National Medicines Policy ${ }^{15}$ and The National Pharmaceutical Service Policy ${ }^{16}$, as guidelines for public access to medicines. According to the Ministry of Health (MS), the supply of medicines and supplies in Brazil is divided into three categories: basic component, specialized component and strategic component $t^{17}$.

The basic component comprises essential medicines and supplies within the scope of Primary Health Care (PHC) that are related to specific diseases and health programs ${ }^{18}$, and the strategic component comprises the medicines and inputs that are needed to prevent, diagnose, treat and control endemic diseases of epidemiological importance, socioeconomic impact or that affect vulnerable populations ${ }^{17}$.

Regarding the specialized component, it includes the majority of high cost medicines. To have access to these medicines, users must fulfill the standards stated in a given CPTG, which is elaborated by a Pharmacy and Therapeutic Committee (PTC) at national or state levels, using evidenced-based criteria ${ }^{19}$. These medicines are 
included in lists published by a national or stated public health authority (normally the ministry and stated secretariat of health, respectively $)^{20,21}$.

This component of the public pharmaceutical services in Brazil is dispensed in high cost public pharmacies, which are guided by the $\mathrm{CPTG}^{22}$. Among the medicines dispensed are long-acting insulin analogues, regulated by the state $\mathrm{CPTG}^{23}$, with an approximate annual care of 987 users with diabetes.

\section{Instrument, collection and compilation of data}

The documents that prove the accomplishment of a given CPTG in a public high cost medicine pharmacy are collected from users and are filed in an "administrative process". Therefore, each user has administrative process of dispensing these high cost medicines. In this study we retrospectively collect the data available in these administrative processes concerning the accomplishment of the inclusion, exclusion and suspension criteria of CPTG related to the long-acting insulin analogue.

The data collection was conducted using a form generated by the free software Epi Info ${ }^{\circledR}$ (http://www.cdc.gov/epiinfo/), and the following information was collected on insulin analogue dispensing administrative processes in a state public system in Brazil: a) socioeconomic data; b) personal history of family diseases and existing diseases; c) current and previous pharmacotherapy; d) monitoring of glycemic levels and HbAlc; and e) identification of inclusion, exclusion or suspension criteria according to the clinical protocol. The data were compiled in a spreadsheet prepared in Microsoft Excel@ version 2007 software.

\section{Study inclusion criteria}

All the administrative processes of the users that requested long-acting insulin analogue in public pharmacies dispensing high cost medicines on Espírito Santo state, Brazil, between January $1^{\text {st }}, 2013$ and December $30^{\text {th }}, 2015$; were included. The period was selected with the intention of covering the opening of the request and the following 12 months after the first episode of user care.

\section{Study exclusion criteria}

We excluded administrative processes of users who did not have 12-month of follow up after the opening of the process, and those with origin in judicial decisions.

\section{Inclusion, exclusion and suspension criteria of the CPTG}

Below, the inclusion, exclusion and suspension criteria of the CPTG are listed:

\section{Inclusion criteria of CPTG}

The protocol establishes the following criteria for the user to be included in the care service ${ }^{23}$ : 1) DM type 1 or type 2 (as proven by laboratory tests), be under intensive treatment with conventional insulin and prove adherence to dietary measures and physical activity; 2) Uncontrolled glycemia, as proven by the following laboratory tests: glycated hemoglobin, fasting glycemia and postprandial glycemia. Three reports of each examination, performed over the 12-month period preceding the application of the medicinal product, must be submitted; 3) Episodes of severe hypoglycemia, as proven by laboratory tests and/ or a capillary check and/or a hospital care report. Exceptions include episodes of hypoglycemia related to physical activity, inadequate diet, intercurrent illnesses or even an inappropriate use of medicines that may interfere with the glycemic levels. Users who report episodes of severe hypoglycemia are included, even if they do not demonstrate glycemic control.

If a user complies with the recommended criteria, compliance will be reassessed quarterly with laboratory tests and medical reports, which are valid for 3 months. For inclusion, the user should present the three criteria or criterion 1 associated with 3 .

\section{Exclusion criteria of the CPTG}

People who use hypoglycemic agents (other than metformin), where insulin is complementary, are excluded. Pregnant women due to the inconsistency of studies demonstrating the safety of the use of these analogues during pregnancy and children less than 6 years of age were also excluded $^{23}$.

\section{Suspension criteria of the CPTG}

The supply of long-acting insulin should be discontinued if the user does not make lifestyle changes (adherence to dietary and physical activity measures). Similarly, the incorrect use of insulin, lack of glycemic monitoring, non-reduction of glycated hemoglobin values $50 \%$ of the glycated hemoglobin value exceeding the normal 
value of the method) and non-reduction of episodes of severe hypoglycemia are criteria of suspension $^{23}$.

\section{Ethical aspects}

The study was approved by the Institutional Board of Ethics in Human Research (CEP/UVV), dated May $14^{\text {th }}, 2014$. It meets the requirements of the National Health Council Resolution 466 of December $12^{\text {th }}, 2012^{24}$.

\section{Statistical analysis}

For a descriptive analysis of the continuous variables, the mean and standard deviation (SD) were calculated. The categorical variables were analyzed by calculating the frequency and proportion. The results were compared using the Wilcoxon test for the glucose, postprandial glucose and HbAlc data. The Kruskal-Wallis test was to compare $\mathrm{HbAlc}$ among the age groups. In both tests, a similarity $<5 \%$ was considered significant. The analyses were performed using STATA software (Stata Corporation, College Station, TX, USA) version 12,0. The data were expressed as mean \pm SD.

\section{Results}

In the period evaluated, 987 administrative processes were registered and approved for the dispensing of long-acting insulin analogues by the public pharmacies in Espírito Santo state. In 466 cases, the opening date was earlier than the initial date of the evaluation period, and for 206 cases, 12 months had not yet elapsed from the opening of the evaluation period; therefore, these cases were excluded. The remaining 315 cases met the inclusion criteria and were analyzed retrospectively. Of these users, 79,5\% had been diagnosed with type $1 \mathrm{DM}$.

The demographic data indicated a gender balance of users, with $50,9 \%$ male and $49.1 \%$ female. The predominant age group was between 18 and 60 years old $(66,7 \%)$. The analyzed processes indicated that $38,7 \%$ of the users had a clinical condition associated with DM, while $61,3 \%$ of the cases contained no such information.

Among the physical activity habits, physical activity was reported in $26,4 \%$ of the processes, and the adoption of dietary measures in 38,5\%. Regarding the DM treatments performed before the beginning of the long-term supply of insulin by the public pharmacies, $96,8 \%$ of these users had previously used other types of insulin.

Table 1 depicts the values of the biochemical tests performed over 12 months prior to the dispensing of long-acting insulin analogues to the users from public pharmacies.

The occurrence of episodes of severe hypoglycemia was reported in $91,3 \%$ of the cases, and most of these events $(99,7 \%)$ were confirmed in the medical care report.

In 2 cases, the occurrence of hypoglycemia was related to physical activity and inadequate diet. Of the users evaluated, the majority used the brazilian public health system, accounting for $56,4 \%$ of the medical records.

Of the analyzed processes, $12 \%$ (38 users) used medicines to treat other clinical conditions, such as hypertension, dyslipidemia, hypothyroidism, kidney problems and depression.

$84,3 \%$ of the users did not use hypoglycemic agents other than metformin concomitant with the regular use of insulin. However, $2 \%$ did use one, and $13,7 \%$ did not mention the information. The use of other types of insulin (Neutral Protamine Hagedorn - NPH and regular) concomitantly with long-acting insulin was verified in $98 \%$ of the users analyzed. This can be explained by the requirement of this protocol of prior regular and NPH insulin use for the release of long-acting analogues ${ }^{23}$. Although the association of more than one type of insulin in the treatment of diabetic patients is important to intensify the response in glycemic control ${ }^{25}$, it was not possible to disclose the percentage of users that has the irrational association of NPH and long-acting analogues from those that were under the right use of regular and long-acting analogues of insulin.

One of the criteria for user follow-up is to monitor glycemia through a quarterly biochemical evaluation. Most of the users (98\%) met the criterion in the first trimester; however, there was variation in the delivery of the reports during the study period (Table 2).

After 12 months initiation of long-acting insulin treatment, the number of users with fast glycemia over $100 \mathrm{mg} / \mathrm{dL}(65,16 \%$ to $63 \%)$ was reduced. Tis did not occur with the values of HbAlc once after the same period increased the number of users with results over than $7 \%$ $(74,41 \%$ to $75,34 \%)$, as shown in Table 3 .

Severe hypoglycemia episodes following the onset of long-acting insulin analogue use were reported in $17,6 \%$ of the cases. Only 2,9\% of the 
Table 1. Values of fasting glucose, postprandial glycemia and glycated hemoglobin (HbAlc) tests performed over 12 months prior to the dispensing of long-acting insulin into public pharmacies.

\begin{tabular}{lrr}
\hline \multicolumn{1}{c}{ Test } & N & \multicolumn{1}{c}{$\begin{array}{c}\text { Test result } \\
(\mathbf{m g} / \mathbf{d L})\end{array}$} \\
\hline Fasting glucose (report 1) & 313 & $175,5 \pm 117,03$ \\
Fasting glucose (report 2) & 306 & $166,4 \pm 105,77$ \\
Fasting glucose (report 3) & 288 & $159,8 \pm 95,78$ \\
Postprandial glycemia (report 1) & 266 & $206,5 \pm 132,87$ \\
Postprandial glycemia (report 2) & 243 & $211,2 \pm 135,48$ \\
Postprandial glycemia (report 3) & 161 & $186,3 \pm 135,22$ \\
HbA1c (report 1) & 294 & $8,7 \pm 2,12$ \\
HbA1c (report 2) & 267 & $8,7 \pm 2,06$ \\
HbA1c (report 3) & 198 & $8,8 \pm 2,23$ \\
\hline
\end{tabular}

Notes: values are reported as the mean \pm S.D.

Source: The authors.

age group. The analysis indicated that glycated hemoglobin levels remained high (above 7\%) in all age groups, even after starting treatment. Users younger than 18 years had glycated hemoglobin values higher than those found in the other age groups (Table 4$)$.

Table 3. Percentage of users with altered values of fasting glucose and glycated hemoglobin (HbA1c) after initiation of long-acting insulin treatment.

Fasting glycemia over $100 \mathrm{mg} / \mathrm{dL}$

\begin{tabular}{lcc}
\hline Tests performed & $\mathbf{N}$ & $\begin{array}{c}\text { Percentage of } \\
\text { users (\%) }\end{array}$ \\
\hline Initial & 310 & 65,16 \\
After 3 months & 190 & 57,36 \\
After 6 months & 244 & 65,16 \\
After 9 months & 204 & 60,78 \\
Final & 300 & 63 \\
\hline \multicolumn{2}{c}{ HbA1c over than 7\% } \\
\hline \multirow{2}{*}{ Tests performed } & $\mathbf{N}$ & Percentage of \\
& 301 & users (\%) \\
\hline Initial & 181 & 74,41 \\
After 3 months & 234 & 73,69 \\
After 6 months & 191 & 75,39 \\
After 9 months & 292 & 75,34 \\
Final & \multicolumn{2}{l}{}
\end{tabular}

Table 2. Values for fasting glucose, postprandial glycemia and glycated hemoglobin (HbAlc) were evaluated each quarter after starting treatment with the long-acting insulin analogue for a period of 12 months.

\begin{tabular}{lcc}
\hline \multicolumn{1}{c}{ Fasting glucose } & Total reports submitted & Test result (mgdL \\
\hline Initial & 310 & $159,7 \pm 116$ \\
After 3 months & 190 & $132,8 \pm 77,9$ \\
After 6 months & 244 & $152,4 \pm 89,9$ \\
After 9 months & 204 & $144,0 \pm 97,00$ \\
Final & 300 & $151,4 \pm 100,09$ \\
\hline \multicolumn{1}{c}{ Postprandial glycemia } & Total reports submitted & Test result (mg/dL) \\
\hline Initial & 288 & $191,4 \pm 124,70$ \\
After 3 months & 174 & $193,6 \pm 128,58$ \\
After 6 months & 223 & $189,0 \pm 131,84$ \\
After 9 months & 185 & $187,7 \pm 137,71$ \\
Final & 281 & $185,2 \pm 118,63$ \\
\hline & Total reports submitted & Test result (\%) \\
\hline Initial & 301 & $8,5 \pm 2,08$ \\
After 3 months & 181 & $8,6 \pm 2,13$ \\
After 6 months & 234 & $8,3 \pm 1,84$ \\
After 9 months & 191 & $8,3 \pm 1,95$ \\
Final & 292 & $8,5 \pm 2,04$ \\
\hline
\end{tabular}

Notes: values are reported as the mean \pm S.D. The Wilcoxon test was used to compare the initial and final values. 
Table 4. Levels of glycated hemoglobin (HbAlc) after starting treatment with long-acting insulin according to age

\begin{tabular}{|c|c|c|c|c|c|c|}
\hline \multirow[t]{2}{*}{ Treatment time } & \multicolumn{2}{|c|}{$<18$ years } & \multicolumn{2}{|c|}{18 to 60 years } & \multicolumn{2}{|c|}{$>60$ years } \\
\hline & $\mathbf{N}$ & HbAlc (\%) & $\mathbf{N}$ & HbAlc (\%) & $\mathbf{N}$ & HbAlc (\%) \\
\hline Initial & 42 & $8,9 \pm 2,9$ & 201 & $8,4 \pm 1,9$ & 58 & $8,3 \pm 1,9$ \\
\hline 3 months & 27 & $9,8 \pm 2,8^{*}$ & 115 & $8,3 \pm 1,8$ & 39 & $8,5 \pm 2,3$ \\
\hline 6 months & 33 & $9,5 \pm 1,9^{*}$ & 157 & $8,2 \pm 1,8$ & 44 & $8,1 \pm 1,8$ \\
\hline 9 months & 27 & $9,7 \pm 2,4^{*}$ & 127 & $8,2 \pm 1,9$ & 37 & $8,0 \pm 1,5$ \\
\hline Final & 39 & $9,5 \pm 2,5^{\star}$ & 199 & $8,3 \pm 2,0$ & 54 & $8,3 \pm 1,7$ \\
\hline
\end{tabular}

Notes: values are reported as the mean \pm S.D.; ${ }^{\star} \mathrm{p}<0.05$, when compared to the mean between the age groups, using the KruskalWallis test.

Source: The authors.

\section{Discussion}

The main finding of the present study was that the supply of long-acting insulin by the pharmacies of a public health system in Brazil failed to strictly comply with the CPTG that determine the rules of its dispensation.

Additionally, no increased benefit of glycemic control for the users was observed since the values of the glycated hemoglobin remained similar after 12 months of use, and the percentage of users with altered parameters remained the same.

The data show that the lack of compliance with the protocol is not only caused by professionals involved in the dispensing of these medicines, but also by the prescribing professionals responsible for the users, since the follow-up of the clinical condition should be evaluated by this professional.

\section{Accomplishment of the inclusion criteria of the CPTG}

The analysis of medical records revealed that inclusion criteria related to evidence of adherence to dietary measures, physical activities and severe hypoglycemia were not adequately observed for insulin dispensing. The practice of physical activity and dietary measures were observed in only $26,4 \%$ and $38,5 \%$ of the cases, respectively, and $8,7 \%$ of the users did not confirm the occurrence of episodes of severe hypoglycemia, which clearly demonstrates non-compliance criteria for the supply of the medicinal product.

According to the $\mathrm{WHO}^{2}$, user education is an important component of the diabetes care service; thus, to adhere to non-medicines therapeutic measures, users must understand the importance of changing lifestyle habits. The litera- ture demonstrates that a diet with a lower calorie intake can reduce symptoms or even reverse the typical hyperglycemia of type $2^{26}$ diabetes and that regular physical activity has a beneficial effect on insulin acting, glucose levels control and metabolic abnormalities associated with diabetes $^{27}$. Thus, the adoption of these measures by the user will contribute to important changes for the control of the disease.

Severe hypoglycemia is the main limitation of the treatment of type 1 and 2 DM since it significantly affects the users' quality of life ${ }^{1}$. Some evidence suggests that insulin analogues have advantages over human insulins because they reduce the episodes of hypoglycemia, thus improving the quality of life of users ${ }^{28}$. A study by Caires de Souza et al. ${ }^{29}$ showed that, when analyzing the frequency and severity of episodes of hypoglycemia together in terms of glycemic control, insulin glargine is superior to other insulin formulations.

The WHO recommends that all health facilities create a PTC to ensure safety in the use of the medicinal product, considering its rational use, clinical and economic efficacy ${ }^{10}$. Among the attributes of the PTC, the following stand out: implement and evaluate strategies to improve the use of medicines; provide ongoing education to the professionals involved; and follow-up and take measures to prevent reactions as well as errors related to the use of medicines ${ }^{10}$. It should be emphasized that one of the challenges is the qualification of the professionals that compose these commissions, as this contributes to improve user care ${ }^{17}$.

However, the present study found that users received long-acting insulin even though they did not meet the essential requirements for safe and effective treatment. According to the United Kingdom National Institute of Clinical Excellence 
(NICE), insulin glargine should be recommended in specific circumstances, and NPH insulin is indicated as the first line of therapy ${ }^{14}$. Developed countries, such as Canada and the United Kingdom, provide insulin analogues only under strict prescription criteria and to groups for which the analogues are advantageous ${ }^{14}$.

Noncompliance with the second inclusion criterion, about glycemic control, was confirmed by laboratory data (fasting glycemia, postprandial glycemia and glycated hemoglobin). In addition, of the 315 cases analyzed, none included the total number of requested laboratory tests, demonstrating that the follow-up of these users was inefficient. According to the American Diabetes Association $(\mathrm{ADA})^{1}$, continuous monitoring of glycemic control is an important tool for assessing the efficacy and safety of the treatment of users with diabetes. The ADA recommends that users with adequate glycemic control should have the glycated hemoglobin test performed at least twice a year and that users who have not achieved glycemic control should be tested quarterly ${ }^{1}$.

\section{Accomplishment of the exclusion criteria of the CPTG}

The results indicated that $2 \%$ of the users who received long-acting insulin met the exclusion criterion related to the concomitant use of oral hypoglycemic agents (other than metformin), and $13,7 \%$ did not present this information. $\mathrm{Na}$ than et al. ${ }^{30}$ suggested that hypoglycemic agents classified as insulin secretagogues (sulphonylurea or glinides) should be discontinued or gradually discontinued because they have no synergistic effects when initiating therapy with insulin injections. The association of insulin with metformin may be effective in reducing glycemia and may also limit weight gain ${ }^{29}$. Therefore, $2 \%$ of the users should not have been included in this care regimen, and in $13,7 \%$ of the cases, it is not possible to state if they agreed because of a lack of information about the use of antidiabetics agents. Thus, it is possible to confirm that these users may be at risk when continuing the use of these analogues.

\section{Accomplishment of the suspension criteria of the CPTG}

The analysis of the biochemical tests showed inefficiencies in user follow-up since the delivery of the reports required for monitoring did not achieve $100 \%$ adherence, nor was verified that the reports presented a reduction in glycated hemoglobin values. In addition, users younger than 18 years of age had increased glycated hemoglobin values compared to baseline values. An emphasis on reducing this value is recommended by the Brazilian Association of Diabetes ${ }^{25}$, which uses it as the gold standard control DM ( $\mathrm{HbA} 1 \mathrm{c}<7 \%)$, as a direct relationship of this parameter and elevated levels of glucose and the development of cardiovascular disease (CVD) exists ${ }^{25}$.

According to the clinical protocol, when the presence of a suspension criterion was observed, the PTC must send a notification to the prescriber; in this way, the PTC can look for alternatives to the user ${ }^{23}$.

The failure of the treatment needs to be detected by the user care commission through technical supervision to guarantee the good quality of care offered ${ }^{10}$. Appropriate supervision involves auditing the results achieved during treatment, as well as communicating and discussing these results with other professionals involved in the care process.

Thus, it can be concluded that the CPTG criteria established by a public health system in Brazil for the dispensing of long-acting insulin analogues were partially fulfilled by the public pharmacies dispensing high cost medicines in the period evaluated. These findings impact the costs of maintaining the service by the health system as well as users' health since glycemic control is not well achieved. In addition, there are users who may be at risk because they should not have received the insulin analogue or should have had it suspended. This scenario compromises the rational use of these insulin analogues.

As recommendations to the public health system, we can state that it is necessary to invest in the training of the professionals involved, aiming to improve the analysis process and the release of the analogues, and also the implementation of pharmacotherapy follow-up by pharmacists for continuous evaluation of the results. These actions will favor the development of a care service that is cost-effective and provides benefits to the users' health.

Additionally, the potential of the present study is the method used to evaluate the compliance with the criteria defined in the CPTG, either for inclusion, exclusion or suspension of treatment with long-acting insulin analogues, and for analysis of the glycemic control of users who use these medicines. This method can be extended to the other various CPTGs in the scope of high-cost medicines dispensing pharmacies in the public 
system, so that the clinical guidelines are indeed fulfilled. In addition, it is important and probably feasible to insert pharmacotherapy follow-up as routine of pharmacies, the orientation of these users and better results in their drug treatment. With this, presumably there will be an innovative direction of public health policies.

\section{Limitations}

Since this was a retrospective study, it was based on only the description of the characteris- tics of users who received long-acting insulin in public pharmacies. Another possible limitation is related to the 12 month of follow-up requested as an inclusion criterion for the study. It is possible that administrative processes were excluded, where users received the medicine for a shorter period of time, but were in accordance with the PCDT or simply suspended. However, the information provided by this study will allow the public health service to become aware of the limitations of the health service, making it possible to improve it.

\section{Collaborators}

FS Moreira worked in the design, analysis and interpretation of data and approved the final version of the manuscript. KOS Cassaro and MM Cruz worked in the analysis of the data, in the drafting of the article and approved the final version of the manuscript. GA Brasil, EM Lima, D Lenz, and DC Endringer worked in the analysis of the data, critically revised the manuscript, and approved its final version. TU Andrade worked in the conception and design of the study, coordinate all the study steps, draft and critically revised the manuscript and approved its final version.

\section{Acknowledgement}

This study was financed in part by the Coordenação de Aperfeiçoamento de Pessoal de Nível Superior - Brasil (CAPES) - Finance Code 001. TU Andrade receives a fellowship from Conselho Nacional de Desenvolvimento Científico e Tecnológico (CNPq).

Our acknowledgement to The Health Secretary of the State of Espírito Santo and FS Moraes. 


\section{References}

1. American Diabetes Association. Standards of Medical Care in Diabetes-2017. Diabetes Care 2017; 40(Supl. 1):S1-S135.

2. World Health Organization (WHO). Global report on diabetes. Geneva: WHO;2016. [cited 2019 Mar 2]. Avaiable from: https://apps.who.int/iris/bitstream/ handle/10665/204871/9789241565257_eng.pdf;jsessionid=D771039A91A5C664655D90A485B0EEF$\mathrm{A}$ ? sequence $=1$

3. International Diabetes Federation (IDF). IDF Diabetes Atlas. Seventh Edition. Bruxelas: IDF; 2015. [cited 2019 Mar 2]. Avaiable from: file:///C:/Users/Vip/ Downloads/IDF_Atlas_7e_2015_EN.pdf

4. Hermanns N, Kulzer B, Kohlmann T, Jacob S, Landgraf W, Theobald K, Haak T. Treatment satisfaction and quality-of-life between type 2 diabetes patients initiating long- vs. intermediate-acting basal insulin therapy in combination with oral hypoglycemic agents--a randomized, prospective, crossover, open clinical trial. Health Qual Life Outcomes 2015; 9(13):77.

5. Guidoni, CM, Oliveira CMX, Freitas O, Pereira LRL Assistência ao diabetes no Sistema Único de Saúde: análise do modelo atual. Brazilian J Pharm Sci 2009; 45(1):37-48.

6. Barceló A, Robles S, White F, Jadue L, Vega J. Una intervención para mejorar el control de la diabetes en Chile. Rev Panam Salud Publica 2001; 10(5):328-333.

7. Asias BD, Stock EM, Small NL, Getchell KE, Patel JR, Krause JD, Cavness S, Dzenowski CL, Ta M. Clinical and financial outcomes of switching insulin glargine to insulin detemir in a veteran population with type 2 diabetes. J Diabetes Metab Disord 2015; 14(53):2-6.

8. Graham R, Mancher M, Miller Wolman D, Greenfield S, Steinberg E. Clinical Practice Guidelines We Can Trust. Institute of Medicine (US) Committee on Standards for Developing Trustworthy Clinical Practice Guideline; 2011.

9. Vinicor F. The public health burden of diabetes and the reality of limits. Diabetes Care 1998; 21(Supl. 3):C15-18

10. World Health Organization (WHO). The world health report 2002: reducing risks, promoting healthy life. Geneva: WHO; 2002. [cited 2019 Mar 2]. Avaiable from: https://apps.who.int/iris/bitstream/handle/10665/ 42510/WHR_2002.pdf?sequence $=1$

11. Ryan MA. Adherence to Clinical Practice Guidelines. Otolaryngol Head Neck Surg 2017; 157(4):548-550.

12. World Health Organization (WHO). Diabetes Mellitus: report of a WHO study group. World Health Organ Tech Rep Ser 1985; 727(1):1-113.

13. Heymann T. Clinical Protocols Are Key to Quality Health Care Delivery. Int J Health Care Qual Assur 1994; 7(7):14-17.

14. Holden SE, Poole CD, Morgan CL, Currie CJ. Evaluation of the incremental cost to the National Health Service of prescribing analogue insulin. BMJ Open 2011; 1(2):1-7.

15. Shafie AA, Ng CH, Tan YP, Chaiyakunapruk N. Systematic Review of the Cost Effectiveness of Insulin Analogues in Type 1 and Type 2 Diabetes Mellitus. Pharmacoeconomics 2017; 35(2):141-162.
16. Brasil. Resolução no 338 de 06 de maio de 2004. Aprova a Política Nacional de Assistência Farmacêutica. Diário Oficial da União 2004; 06 maio.

17. Brasil. Portaria no 2.583 de 10 de outubro de 2007 Define elenco de medicamentos e insumos disponibilizados pelo Sistema Único de Saúde, nos termos da Lei no 11.347 , de 2006, aos usuários portadores de diabetes mellitus. Diário Oficial da União 2007; 10 out.

18. Brasil. Portaria no 1.555 de 30 de julho de 2013. Dispõe sobre as normas de financiamento e de execução do Componente Básico da Assistência Farmacêutica no âmbito do Sistema Único de Saúde (SUS). Diário Oficial da União 2013; 30 jul.

19. Brasil. Portaria no 1.554 de 30 de julho de 2013. Dispõe sobre as regras de financiamento e execução do Componente Especializado da Assistência Farmacêutica no âmbito do Sistema Único de Saúde (SUS). Diário Oficial da União 2013; 30 jul.

20. Brasil. Ministério da Saúde (MS). Relação Nacional de Medicamentos Essenciais: RENAME 2014. 9ed. Brasília: MS; 2015. 230 p.

21. Espírito Santo. Relação Estadual de Medicamentos: REMEME 2016. [cited 2019 Mar 2]. Disponível em: https://farmaciacidada.es.gov.br/Media/farmaciacidada/Arquivos/REMEME\%202016\%20 completa_24_11_2016.pdf. Acessado em julho de 2017.

22. Portaria $\mathrm{n}^{\circ}$ 56- $\mathrm{R}$ de 24 de agosto de 2007. Aprova a implantação e expansão do Projeto Farmácia Cidadã Estadual. Diário Oficial do Espírito Santo 2007; 27 ago.

23. Portaria $n^{\circ} 167-R$ de 18 de outubro de 2011. Estabelece critérios para a dispensação de análogo de insulina de longa ação disponibilizada pela Secretaria de Estado da Saúde do Espírito Santo e monitoramento terapêutico. Diário Oficial do Espírito Santo 2012; 11 jun.

24. Brasil. Resolução no 466 de 12 de dezembro de 2012. Aprova as diretrizes e normas regulamentadoras de pesquisas envolvendo seres humanos. Diário Oficial da União 2012; $12 \mathrm{dez}$.

25. Sociedade Brasileira de Diabetes (SBD). Diretrizes da Sociedade Brasileira de Diabetes 2015-2016. São Paulo: A.C. Farmacêutica; 2016.

26. Taylor R. Type 2 diabetes: etiology and reversibility. Diabetes Care 2013; 36(4):1047-1055.

27. Joiner KL, Nam S, Whittemore R. Lifestyle interventions based on the diabetes prevention program delivered via eHealth: A systematic review and meta-analysis. Prev Med 2017; 100:194-207.

28. Monami M, Marchionni N, Mannucci E. Long-acting insulin analogues vs. NPH human insulin in type 1 diabetes. A meta-analysis. Diabetes Obes Metab 2009; 11(4):372-378.

29. Caires de Souza AL, Assis Acurcio F, Guerra Júnior AA, Rezende Macedo do Nascimento RC, Godman B, Diniz LM. Insulin glargine in a Brazilian state: should the government disinvest? An assessment based on a systematic review. Appl Health Econ Health Policy 2014; 12(1):19-32. 
30. Nathan DM, Buse JB, Davidson MB, Ferrannini E, Holman RR, Sherwin R, Zinman B. American Diabetes Association; European Association for Study of Diabetes. Medical management of hyperglycemia in type 2 diabetes: a consensus algorithm for the initiation and adjustment of therapy: a consensus statement of the American Diabetes Association and the European Association for the Study of Diabetes. Diabetes Care 2009; 32(1):193-203.

Article submitted 09/03/2019

Approved 07/08/2019

Final version submitted 09/08/2019

Chief Editors: Romeu Gomes, Antônio Augusto Moura da Silva 